\title{
LA CIRCULACIÓN DEL CONOCIMIENTO EN LA CREACIÓN DEL DISCURSO GEOGRÁFICO DE SIERRA NEVADA EN EL S. XIX
}

\author{
C. CORNEJO NIETO
}

Departamento de Geografía, Universidad Autónoma de Madrid.

\begin{abstract}
RESUMEN. El primer conocimiento geográfico riguroso de Sierra Nevada se produjo en la primera mitad del siglo XIX. Mientras que se ha estudiado la historia de tal conocimiento, así como la genealogía de las figuras que la hicieron posible, aún no se ha investigado la aproximación científica al macizo nevadense dentro del marco global del discurso geográfico europeo de la época. El presente artículo ofrece una primera contextualización en el pensamiento geográfico de su tiempo en términos conceptuales, metodológicos y retóricos a través de varios modelos de representación, empleando, para ello, una metodología de carácter hermenéutico a partir del análisis de documentación textual e iconográfica. El trabajo propone, como hipótesis principal, que los procedimientos metodológicos, las prácticas científicas y los modelos gráficos de representación de la alta montaña, configurados por la normativización de las ciencias de la Tierra hacia 1800, fueron transmitidos desde casos foráneos de estudio, como los Alpes y Pirineos, hasta Sierra Nevada. Allí, fueron aplicados a la montaña nevadense, contribuyendo así a la definición de los primeros estudios sobre la naturaleza del macizo. Sin embargo, los contenidos de aquellos modelos fueron, al mismo tiempo, readaptados a la realidad geográfica de la Sierra. Por ello, el artículo explora asimismo las transformaciones del paradigma foráneo de la montaña sufridas en su aplicación al macizo bético atendiendo a sus particularismos geográficos, pertenecientes a la tipología de alta montaña mediterránea. Para ilustrar esta transmisión del discurso geográfico del siglo XIX, se utiliza el marco teórico de la circulación y reinterpretación del conocimiento, de escasa recepción en la Geografía española.
\end{abstract}

The circulation of knowledge in the making of the geographic discourse of Sierra Nevada in the 19th century

ABSTRACT. The first accurate geographical knowledge of Sierra Nevada was produced in the first half of the nineteenth century. While the history of such knowledge, as well as the genealogy of the leading figures who made it possible, have been addressed, the location of the first scientific approach to Sierra Nevada within the global framework of the geographical discourse in the nineteenth- 
century Europe has not been investigated yet. This article offers an approach to its conceptual, methodological and rhetorical contextualization through diverse models of representation, employing a hermeneutic methodology based on the analysis of textual and iconographic documentation. The main hypothesis of the paper suggests that the methodological procedures, scientific practices and rendering models of the high mountain, shaped by the regulation of European geographical sciences, were transmitted from chains such as the Alps and Pyrenees to the Sierra Nevada. They were applied to the Sierra, thus contributing to the definition of the first studies on the nature of the massif. However, the ideas included in those models were, at the same time, readapted to the material reality of the Sierra. Thus, the article explores the changes of the foreign paradigm of the mountain undergone in the Andalusian massif depending on their geographical particularities, belonging to the Mediterranean high mountain. In order to illustrate this transmission of the nineteenth-century geographical discourse, the paper uses the theoretical framework of the circulation and reinterpretation of knowledge, of little reception within the Spanish Geography.

Palabras clave: Sierra Nevada, representaciones científicas, circulación del conocimiento, visión panorámica, montaña insular.

Key words: Sierra Nevada, scientific renderings, circulation of knowledge, panoramic view, insular mountain.

Enviado el 15 de septiembre de 2014 Aceptado el 23 de febrero de 2015

*Correspondencia: Departamento de Geografía, Universidad Autónoma de Madrid. E-mail: carlos.cornejo@uam.es; soy.carlos@yahoo.es

\section{Introducción}

El macizo de Sierra Nevada es una cadena montañosa ubicada en la Zona Interna Bética, dentro de los Sistemas Béticos. Según su origen geológico y estructural, forman, junto con el Rif, el arco Bético-Rifeño que se eleva junto al Mediterráneo. Alberga las cumbres más altas de la península Ibérica, constituyendo el macizo de alta montaña más meridional de Europa y el segundo en altitud después de los Alpes. Su verticalidad y cercanía al mar han determinado unas condiciones bioclimáticas muy particulares, las cuales, y a pesar de tal altitud, le ha conferido al macizo una morfología menos alpina que las grandes cordilleras europeas.

La Geografía y otras ciencias humanas han abordado ampliamente la historia del conocimiento geográfico de los sistemas montañosos de Occidente. Debido a su preeminencia hegemónica como canon de alta montaña europea, la cordillera de los 
Alpes ha encarnado mayoritariamente este objeto de estudio (Joutard, 1986; Broc, 1991; Ring, 2000; Guichonnet et al., 2002; Reichler, 2002; Walter, 2005, Beattie, 2006). Otros trabajos han tratado la historia del progresivo conocimiento del Pirineo a través de herramientas que se han situado entre las ciencias geográficas, las artes plásticas, la literatura, la cartografía y el montañismo (Beraldi, 1977; Saule-Sorbé, 1993; Briffaud, 1994; Saule-Sorbé, 2010), así como de otras cordilleras y montañas periféricas (Mac Neill, 1992; Frolova, 2006; Della Dora, 2011). La Geografía española también se ha interesado por la historia del conocimiento científico de la alta montaña ibérica. Estos estudios han tendido a centrarse en la imbricación del discurso geográfico con otro tipo de retóricas, concibiendo la montaña como un modelo cultural, social e ideológico (Martínez de Pisón, 1998; Ortega Cantero, 2001; González Trueba y Serrano Cañadas, 2007; Ortega Cantero, 2012). Respecto a Sierra Nevada, Manuel Titos Martínez (1997, I y II) ha desvelado las facetas intelectuales que intervinieron en el conocimiento científico y cultural de Sierra Nevada desde la Ilustración. Por su parte, Antonio Gómez Ortiz ha investigado el valor de la producción gráfica de los siglos XVIII y XIX como indicadores documentales del clima de la Pequeña Edad del Hielo (Gómez Ortiz, 2004; Gómez Ortiz y Plana Castellví, 2006; Gómez Ortiz et al., 2008). Recientemente, se ha abordado el estudio de sus imaginarios geográficos de evocación alpina creadas por los viajeros anglosajones del siglo XIX (Cornejo Nieto, 2014).

Sin embargo, en estos estudios se ha prestado poca atención al valor intrínseco de los diferentes modelos científicos de representación del estudio geográfico de la montaña española a favor de las cualidades estéticas o simbólicas de otro tipo de imágenes. Las representaciones de origen y contenido científico -en este caso, dentro del ámbito de las ciencias de la Tierra- han servido para conceptualizar y normativizar el valor geográfico de las áreas de montaña. Por ello, es importante el estudio de aquellas tipologías que han servido de modelos metodológicos y cognitivos para el estudio geológico, biogeográfico y fisiográfico de las cordilleras. En este sentido, aún están pendientes de investigar los discursos y las teorías a partir de las cuales se conformaron dichas imágenes, sus diferentes tipos iconográficos, los contextos de dichos modelos en el desarrollo histórico de las teorías geográficas, y las relaciones epistemológicas y metodológicas que pudiera haber entre ellos.

Por todo ello, este artículo pretende examinar y contextualizar los modelos de representación empleados en las primeras contribuciones científicas sobre Sierra Nevada en el marco de las expediciones naturalistas a la montaña acometidas en la primera mitad del siglo XIX. Para abordar el trabajo, se han escogido dos casos de estudio concretos, ya que representan las primeras sistematizaciones del macizo en los campos de la geología y la biogeografía: las investigaciones de Simón de Rojas Clemente Rubio en 1804 y 1805, y los trabajos de Edmond Pierre Boissier en 1837. Mediante el análisis de sus imágenes del macizo y de su relación con varias representaciones de otras cordilleras extrapeninsulares, se discute la transmisión conceptual y metodológica del conocimiento europeo de la alta montaña a Sierra Nevada. 


\section{Consideraciones teóricas: la circulación del conocimiento geográfico a través de las imágenes}

Como ha sostenido Edward Said (1991, 226), las teorías científicas "están normalmente alimentadas [...] por [una] circulación de ideas" que "conlleva procesos de representación e institucionalización diferentes de aquellos de su foco de origen". Recientes estudios han abordado el movimiento y las transformaciones de las "culturas de la historia natural" a través de diversas "formas culturales impresas" (Jardine et al., 1995). De esta forma, la circulación del conocimiento ha sido posible gracias a las relaciones mutuas entre la ciencia y la literatura, posibilitando un intercambio de formas e información del discurso científico a través de la interacción entre los textos, los instrumentos y las imágenes (Beer, 1996; Secord, 2004). Dentro de la disciplina de la Geografía, David Livingstone ha analizado la importancia de la espacialidad en la transmisión y reinterpretación del discurso científico. Así, ha investigado el significado de la ubicación geográfica en la movilidad de las teorías y sus formas impresas, concediendo una importancia capital a la manera en que los espacios y lugares "permiten y constriñen el discurso" de origen exógeno (Rupke, 2000; Livingstone, 2003, 2005, 399; Withers y Livingstone, 2011).

Como ha indicado Luc Pauwels (2006, vii), las imágenes constituyen "una parte fundamental del discurso científico", y, por ende, un elemento esencial en el proceso de trasmisión de las ideas científicas y geográficas (véase también Cosgrove, 2008; Secord, 2011). En este sentido, la montaña como objeto de investigación de las ciencias de la tierra ha dado lugar a unos particulares modelos de representación. En los siglos XVIII y XIX, estas imágenes tuvieron como objetivo alejarse de lo arquetípico y "reproducir para el ojo no familiarizado la novela de la tierra" que las ciencias naturales se encargarían de revelar (Stafford, 1984, 40). Para ello, se crearon dos modelos fundamentales de representación a través de los cuales se vehicularon las primeras investigaciones geográficas de la montaña. La primera, inserta en el ámbito de la geología, obedeció a la utilización de la visión panorámica desde la cumbre con el propósito de desvelar el orden topográfico y la disposición geológica de las cordilleras. La segunda, dentro del campo de la biogeografía, se basó en la idea de la montaña como un espacio insular, capaz de albergar una gran riqueza biológica. El artículo recoge cómo se forjaron ambos modelos gráficos con el fin de analizar de qué manera circularon hasta Sierra Nevada para configurar allí el primer discurso geográfico moderno del macizo.

\section{La transmisión de los modelos de representación geológica de la montaña}

\subsection{La visión global desde la cumbre: en busca del orden geográfico de las montañas}

Los primeros científicos de la tierra comenzaron a interesarse por la comprensión del orden global de la superficie terrestre desde las propias cumbres de las cordilleras, desde donde se ejerció una nueva forma de mirar la naturaleza (Broc, 1969; Briffaud, 1989; Broc, 1991; Reichler, 2002). El inmenso panorama descubierto desde lo alto "revel[ó] súbitamente un orden topográfico". Esta nueva mirada tuvo un "papel rector" en la formulación de las "normas perceptivas" de las ciencias geográficas, poniendo de 
relieve la existencia, a un nivel tanto visual como epistemológico, del espacio de la alta montaña (Briffaud, 1989, 446, 421-422).

El primer científico que encarnó esta visión de la alta montaña fue el ginebrino Horace-Bénédict de Saussure (1740-1799), autor del célebre Voyages dans les Alpes, publicado entre 1779 y 1796. En sus expediciones, Saussure pretendió obtener un dominio visual completo del espacio desde la cumbre del Mont Blanc con el fin de resolver la estructura de la cordillera. Producto de esta mirada global a la montaña fueron los modelos de representación publicados en sus Voyages, que constituyeron patrones universales para los primeros estudios geográficos del relieve de los sistemas montañosos. Estos modelos constaron, por un lado, de vistas panorámicas, compuestas por dibujos, diagramas, croquis o écfrasis narrativas; y, por otro, de tours d'horizon, representaciones anamórficas dibujadas a mano alzada. Los panoramas fueron "dibujos concebidos con una mirada angular", mediante los cuales se buscó registrar "el espacio que la mirada del espectador es capaz de abarcar desde un punto concreto" (Naranjo Ramírez y López Ontiveros, 2011). Los tours d'horizon aludieron a vistas panorámicas completas de $360^{\circ}$ que reproducían el alzado del relieve, expresando la "noción de totalidad" percibida desde las cumbres (Comment, 2002, 166).

Las vistas panorámicas de la montaña alpina se hallaron presentes en toda la obra de Saussure. En ellas, el ginebrino aplicó el ejercicio de la visión global sobre los Alpes, cuyos resultados mostró en varios "Coup-d'oeil" (vistas generales) de diversos sectores de la cordillera, que le sirvieron para reconstruir visualmente su orden geográfico (véase Saussure, 1779, III, 102-103). Asimismo, su obra incorporó la primera vista circular de la alta montaña, Vue circulaire des Montagnes qu'on découvre du sommet du Glacier de Buet, levantada entre 1766 y 1770 por el escritor y dibujante Marc-Théodore Bourrit para su libro Description des glacières et glaciers de Savoye, publicado en 1773. En esta conocida imagen, Bourrit y Saussure pusieron de manifiesto la función cardinal de la mirada holística del geólogo en el estudio del relieve, presentando la cordillera como una totalidad envolvente dispuesta a ser ordenada.

Los modelos gráficos de análisis de las montañas circularon desde el mundo alpino hasta los Pirineos. Louis-François Ramond de Carbonnières (1755-1827), conocedor de la obra de Saussure, adoptó el mismo procedimiento visual desde las cumbres del Monte Perdido. En 1801, publicó Voyages au Mont-Perdu et dans la partie adjacente des Hautes-Pyrénées. En su obra, el empleo de la mirada panorámica al espacio geográfico fue también trasladado a las representaciones de los perfiles de la montaña, en su caso mediante dibujos-diagrama realizados por él mismo. Estas imágenes ilustraron las hipótesis de Ramond sobre la disposición de los materiales calcáreos del macizo pirenaico. Una de ellas mostró la vista completa del Monte Perdido adquirida desde la cima del Pimené (Fig. 1), la cual "reunía todos los objetos que había examinado de forma aislada, y que escondía [...] todas las relaciones generales que mediante las observaciones detalladas solo estaban entregadas a conjeturas" (Ramond de Carbonnières, 1801, 283-284). Sobre la cumbre, por tanto, "una mirada era suficiente; el caos estaba desenredado" (Ramond de Carbonnières, 1789, 45). 


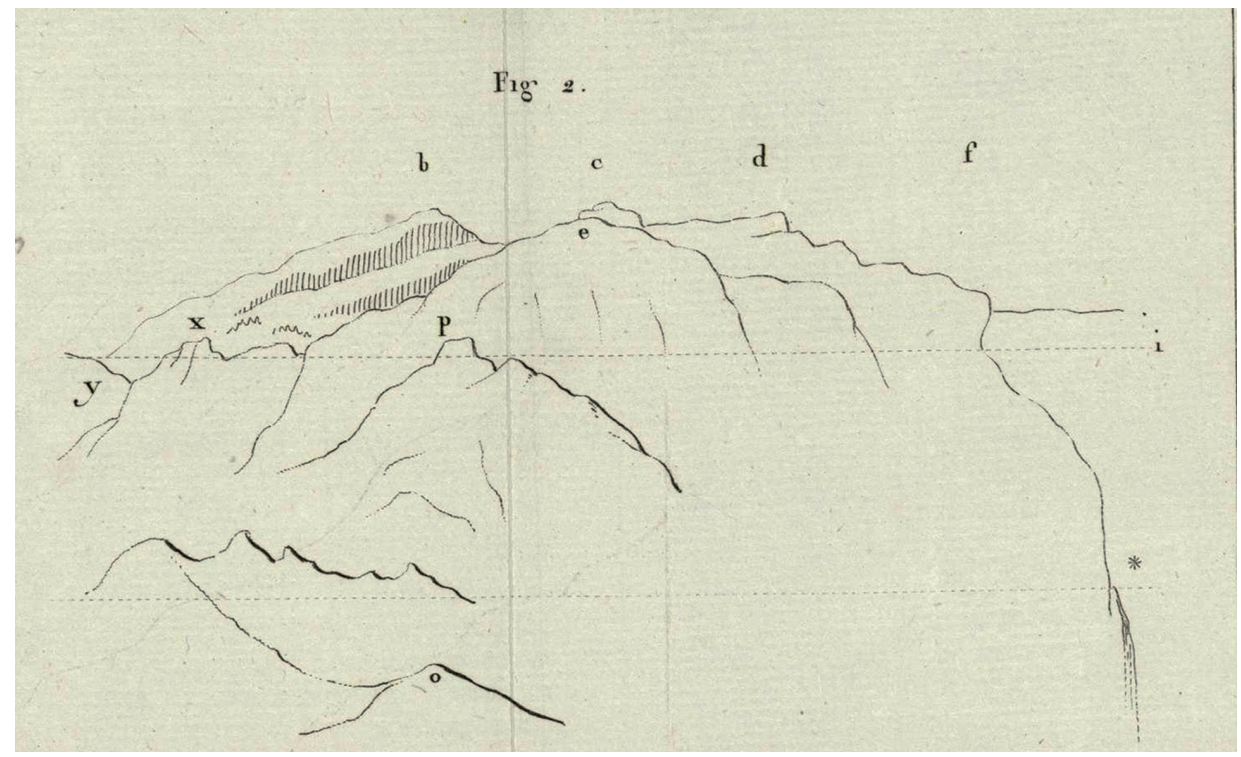

Figura 1. Louis Ramond de Carbonnières: [vista del macizo del Mont-Perdu desde la cima del Pimené]. Dibujo a plumilla. Fuente: Ramond de Carbonnières (1801).

Las vistas circulares y panorámicas del Mont-Blanc y del Monte Perdido mostraron la función reveladora de la mirada humana en el primer conocimiento topográfico y fisiográfico de las cordilleras. Ambos formatos presentaron la montaña como materia "legible" y "penetrable", susceptible de descifrar (Stafford, 1984, 285). Con ellos, nació la geología "como práctica", como "marco de representación de lo real”, y como discurso "normativo" de la montaña (Briffaud, 1989, 424-425).

\subsection{La mirada global a Sierra Nevada: en busca del orden topográfico del macizo}

Sierra Nevada no quedó al margen de esta nueva práctica normativa. El primer acercamiento al estudio geográfico del macizo estuvo determinado por la utilización de este procedimiento visual. Simón de Rojas Clemente Rubio (1777-1827) fue el primer naturalista que subió a Sierra Nevada para llevar a cabo, entre 1804 y 1805, y en 1809, un trabajo sistemático de medición y nivelación de las cumbres, y de herborización de un gran número de plantas. Su viaje a la Sierra, inserto en el marco de los nuevos proyectos científicos promovidos por el Real Jardín Botánico de Madrid, formó parte del proyecto estatal para estudiar la vegetación silvestre y cultivada del país (Capel Sáez, 2002). Su trabajo, Historia natural del Reino de Granada, fue depositado en el Archivo del Jardín Botánico, donde permaneció inédito hasta el año 2002.

En sus anotaciones, Clemente Rubio incluyó descripciones geográficas del relieve de las montañas nevadenses, información sobre su caracterización vegetal y mineralógica, y datos sobre la organización de las formaciones rocosas del macizo (Mateu Bellés, $2008,374)$. Como buen conocedor de las últimas investigaciones en geología llevadas a 
cabo en Europa a finales del siglo XVIII, hizo referencia a la doctrina de Dolomieu, mencionó las investigaciones de Saussure en los Alpes y citó igualmente algunos fenómenos de la montaña observados por Ramond, así como sus herborizaciones efectuadas en el Pirineo (Capel Sáez, 2002; Clemente y Rubio, 2002, 646). Asimismo, se mostró muy atraído por las últimas investigaciones del geólogo catalán Carlos de Gimbernat sobre el origen de las montañas alpinas. A través del conocimiento de su obra, el botánico español adoptó "los planteamientos neptunistas de Werner", distinguiendo así "entre terrenos 'primitivos' y 'secundarios”, y proponiendo, tal y como había formulado Ramond en los Pirineos, "la existencia entre ellos de otros ‘de transición”" (Capel Sáez, 2002, 26).

Este conocimiento de las novedades científicas de su tiempo le llevó a adoptar los procedimientos utilizados en los estudios geológicos del continente. Así, Clemente Rubio aplicó la mirada global al espacio geográfico de la montaña en la búsqueda de su orden topográfico y de la disposición de sus formaciones rocosas. Para ello, empleó varias formas de representación, como la écfrasis, los dibujos panorámicos y los croquis. El científico español ofreció varias descripciones del cordal de las altas cumbres de la Sierra, aportando información sobre su orientación y la caracterización de su relieve (Clemente y Rubio, 2002, 2012): "Desde el Puerto de Bacares se veían correr de N.O. 1/4 al Oeste a S.E. 1/4 al Este los Cerros con este orden: Veleta, los Machos, el de la Laguna de la Caldera, la Alcazaba, Mulhacén, Tajo Negro, sobre la Laguna de Bacares. [...] El Cerro de Mulhacén tiene su corte o tajo al N.N.O., como todos los demás, excepto el de los Machos y Veleta, que están cortados desde el punto de Sur hasta el de N.E., siendo el corte mucho más profundo desde el punto del Este al N.E.".

Sus observaciones sobre la geognosia del macizo resultaron igualmente interesantes. Consciente de la máxima de Ramond y Saussure, según la cual una sola mirada al conjunto bastaba para esclarecer el caos y "despejar las dudas" que el trabajo de gabinete no aclaraba, Clemente Rubio ascendió sistemáticamente a las cumbres de la Sierra con el fin de examinar su cordal principal. En lo alto del Veleta, desde donde, afirmaba, esperaba "[satisfacer] mi curiosidad impaciente", el científico español observó las "capas esquistosas" del eje central de Sierra Nevada (2002, 648): "Hasta Veleta solo las vi de lejos. En alguna parte me parecían horizontales y tal vez es éste el caso, en otros me parecían inclinadas hacia el Sur, aunque tanto menos cuanto más centrales, en ninguna verticales". Determinó que "la pizarra de Sierra Nevada es muy compacta y oculta por esto su estratificación". En el Veleta constaba "de bancos gruesos y confusos dirigidos hacia el Sur", en el Mulhacén, "corren hacia el Norte, y los de la loma "que corre entre Veleta y Mulhacén miran a este último".

Estas descripciones de la Sierra, al tiempo que revelaron el interés de Clemente Rubio por el estudio del macizo como un "cuerpo geográfico" completo -como indicó en el prólogo $(2002,95)$-, evidenciaron una postura epistemológica heredera de los criterios marcados por los métodos científicos foráneos. Como en los casos de Saussure y Ramond, el potencial de la mirada desplegada por el científico español en Sierra Nevada se trasladó a su imagen gráfica. Durante sus trabajos de nivelación del Mulhacén, reunidas en La Geografía del Reino de Granada (Clemente y Rubio, 1827), Clemente Rubio realizó algunos panoramas parciales de las cumbres de la Sierra. Uno de los perfiles 
más completos fue la Vista de la parte principal (septentrional) de Sierra Nevada, tomada desde la cumbre del Calar de Güéjar (Fig. 2). La ilustración informaba, en clave toponímica, de los elementos geográficos principales, y las notas del científico ofrecían una descripción topográfica para la comprensión del relieve (Clemente y Rubio, 2002, 1090-1091): "JJ: Loma que aparece alta desde Guadarnón y baja por el lado opuesto a su espalda, se pierde el lomo [...]. Loma hacia el remate de cuya falda meridional se reúnen algunos barranquitos [...] para reunirse todos ya juntos con el de Valdeinfierno [...]. A: Peña de los Perros. Veleta aparece en vista mayor que Mulhacén por estar más cerca y ser más delgado [...]. Se veía el lomo o parte no tajada de Mulhacén que tira al Barranco de Poqueira. Desde esta línea hasta el punto K sigue tajada toda la cumbre. [...] Veleta: se ve su tajo vertical...".



Figura 2. Simón de Rojas Clemente y Rubio: Vista de la parte principal (septentrional) de Sierra Nevada, tomada desde la cumbre del Calar de Güéjar, 1804-05. Dibujo con tinta negra y sepia sobre papel verjurado. Madrid, Real Jardín Botánico. Fuente: Clemente y Rubio (2002).

En Vista de Mulhacén cet. desde la cumbre del Veleta, el botánico se centró en la representación del tajo septentrional del Mulhacén y el perfil de la Alcazaba (Fig. 3). En las anotaciones de la ilustración, hacía evidente de nuevo su interés por la toponimia y la organización del cordal (Clemente Rubio, 2002, 1095): "Vista de Mulhacén, etc. desde la cumbre de Veleta. De c está perfectamente tajada la cumbre. Lo rojizo es nieve. a. Mulhacén. b. La Alcazaba. c. A su Oriente está la Caldera. nnn. Cuerda central que desde Mulhacén corre a Veleta. oo. Base de Veleta por el lado del Corral”. El reverso 
del dibujo incluyó un croquis del Corral de Veleta. En su ascensión al Picacho en agosto de 1805, intentando comprender la disposición de los materiales rocosos del Picacho y el Mulhacén, el botánico especuló sobre la formación orogénica del Corral (Clemente Rubio, 2002, 648): "la gran catástrofe que tajó a los dos grandes picachos y formó el Corral de Veleta hizo desaparecer el eje central que, habiendo quedado más bajo que otros puntos inmediatos a él yace oculto, entre los escombros de estos y sus propias ruinas en los tajos de Mulhacén y Veleta".

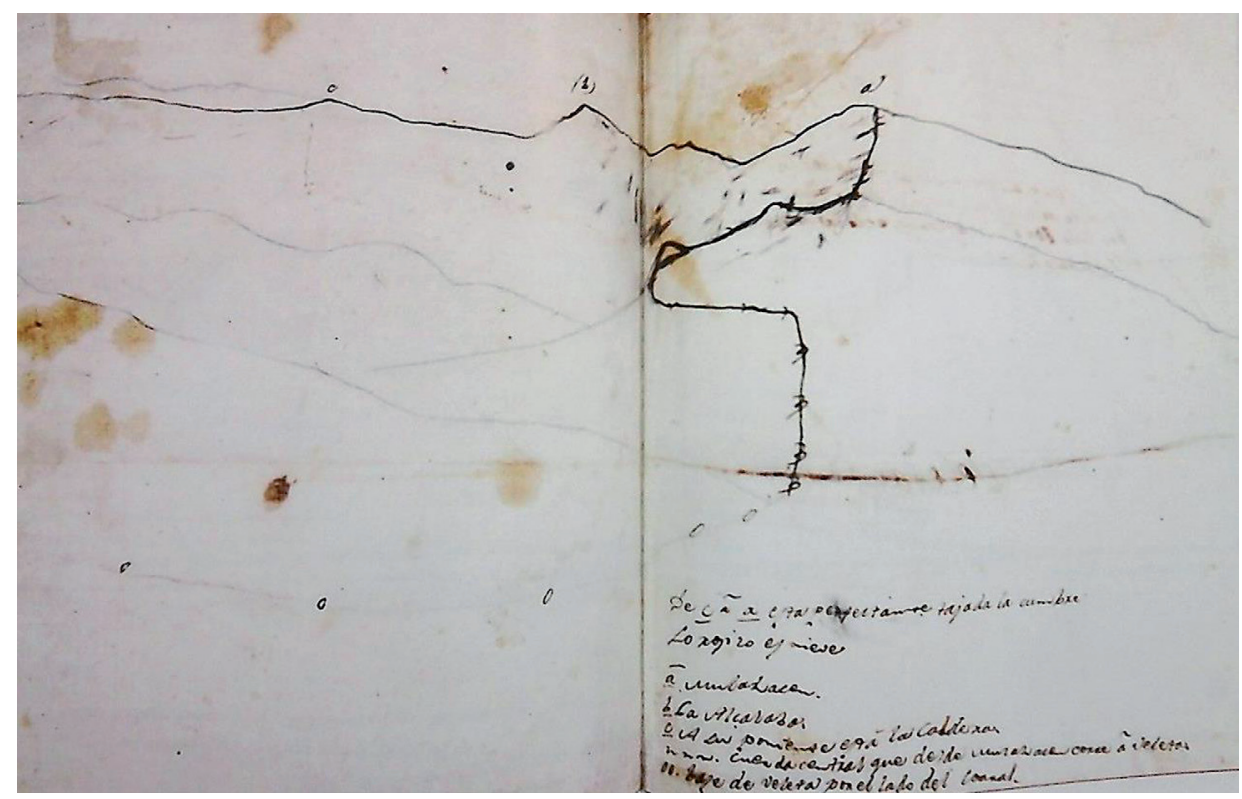

Figura 3. Simón de Rojas Clemente y Rubio: Vista de Mulhacén cet. desde la cumbre del Veleta, 1805. Dibujo con tinta sepia y lápiz sobre papel verjurado. Madrid, Real Jardín Botánico. Fuente: Clemente y Rubio (2002).

Los perfiles y croquis realizados por Clemente Rubio mostraron otra realidad de la montaña nevadense, hasta entonces carente de representación. Sus imágenes aportaron la primera información topográfica esencial para el estudio del macizo, recogida a partir de las expediciones a la alta montaña. Mediante el empleo de la visión global desde la cumbre, pretendió darle a Sierra Nevada un orden geográfico, observando la formación de su materialidad rocosa, que, por vez primera, apareció legible en términos científicos.

\section{La transmisión de los modelos de representación biogeográfica de la montaña}

\subsection{La montaña como modelo insular: la formación del canon}

Desde la Ilustración, la montaña se ha presentado como un espacio "excepcional y aislado", como un auténtico "modelo insular" geográfico. Basada en esta idea, en la primera mitad del siglo XIX la conocida entonces como geografía de las plantas estableció 
otro modelo de representación a través del cual analizar las características biogeográficas de las áreas de montaña. Esta concepción excepcionalista de la montaña trajo consigo dos consecuencias importantes para sus modelos de representación. Por un lado, el modelo de la "isla-montaña original" y las posteriores propuestas de los pisos de vegetación hizo que la geografía vegetal derivara "hacia una ecología", la cual puso "en relación los organismos vivos con las condiciones medioambientales". Por otro lado, introdujo la noción del endemismo, subrayando la riqueza de la flora y la fauna de las áreas montañosas. De esta forma, la alta montaña adquirió el significado de un "microcosmos" que albergaba "las leyes universales que ayudan a comprender la organización geográfica del mundo" (Frolova, 2006, 26-27; véase también Capel, 1981; Buttimer, 2001). Se conformó así un modelo convencional de representación dentro de las ciencias geográficas en el que las relaciones entre la altitud, el clima y la vegetación determinaron la zonificación vertical de la montaña en pisos de vegetación.

Entre 1799 y 1804, Alexander von Humboldt fijó dicho modelo biogeográfico en sus estudios del Teide y de las montañas sudamericanas, convirtiéndose en referentes metodológicos para el estudio botánico de otras zonas de montaña (Dettelbach, 1999; Godlewska, 1999; Briffaud, 2006; Gómez Mendoza y Sanz Herráiz, 2010). En ellos, vinculó los organismos vivos con los criterios medioambientales y geográficos del espacio que habitaban. Para ilustrar estas relaciones, Humboldt creó los tableaux physiques, o cuadros físicos de la naturaleza, que tradujeron iconográficamente estas relaciones. El paradigma de sus tableaux estuvo encarnado por el célebre perfil del Chimborazo Géographie des plantes équinoxiales. Tableau physique des Andes et Pays voisins, publicado en el Essai sur la géographie des plantes en 1805 (Fig. 4). La lámina acentuó el aislamiento de la montaña y destacó la relación entre las variables ambientales y geográficas y los pisos de vegetación, estableciendo, con ello, las leyes universales que explicarían la organización del mundo natural.

La imagen del volcán andino encarnó, además, las implicaciones de la nueva epistemología humboldtiana de la ciencia. El estudio de las plantas efectuado por Humboldt se mostró contrario a la clasificación del mundo natural ofrecida anteriormente por Linneo, cuyo sistema de representación no permitía las interconexiones de los elementos de la naturaleza, revelando una visión estática y abstracta del mundo vegetal. Por el contrario, el científico prusiano reveló "el continuo de la naturaleza [...] distinto del análisis de las palabras" encarnado por el sistema linneano, presentando así un "espacio real, geográfico y terrestre" donde "los seres [aparecían] embrollados unos con otros" en una suerte de “azar, desorden y perturbación” (Foucault, 1989, 148-149).

El prototipo de montaña codificado por Humboldt a partir del estudio del Chimborazo constituyó el paradigma universal para el estudio de los pisos de vegetación. Esto desencadenó toda una serie de imágenes de escalonamiento de pisos biogeográficos que fueron aplicados a distintas cordilleras de diversas latitudes y zonas climáticas. Debido a su homogénea distribución vegetal, los Alpes centrales representaron, en Europa, el canon de tal zonificación. Pero, partiendo de la aplicación del modelo humboldtiano al mundo alpino, Sierra Nevada se convirtió, asimismo, en un prototipo ejemplar de montaña insular y excepcional. 


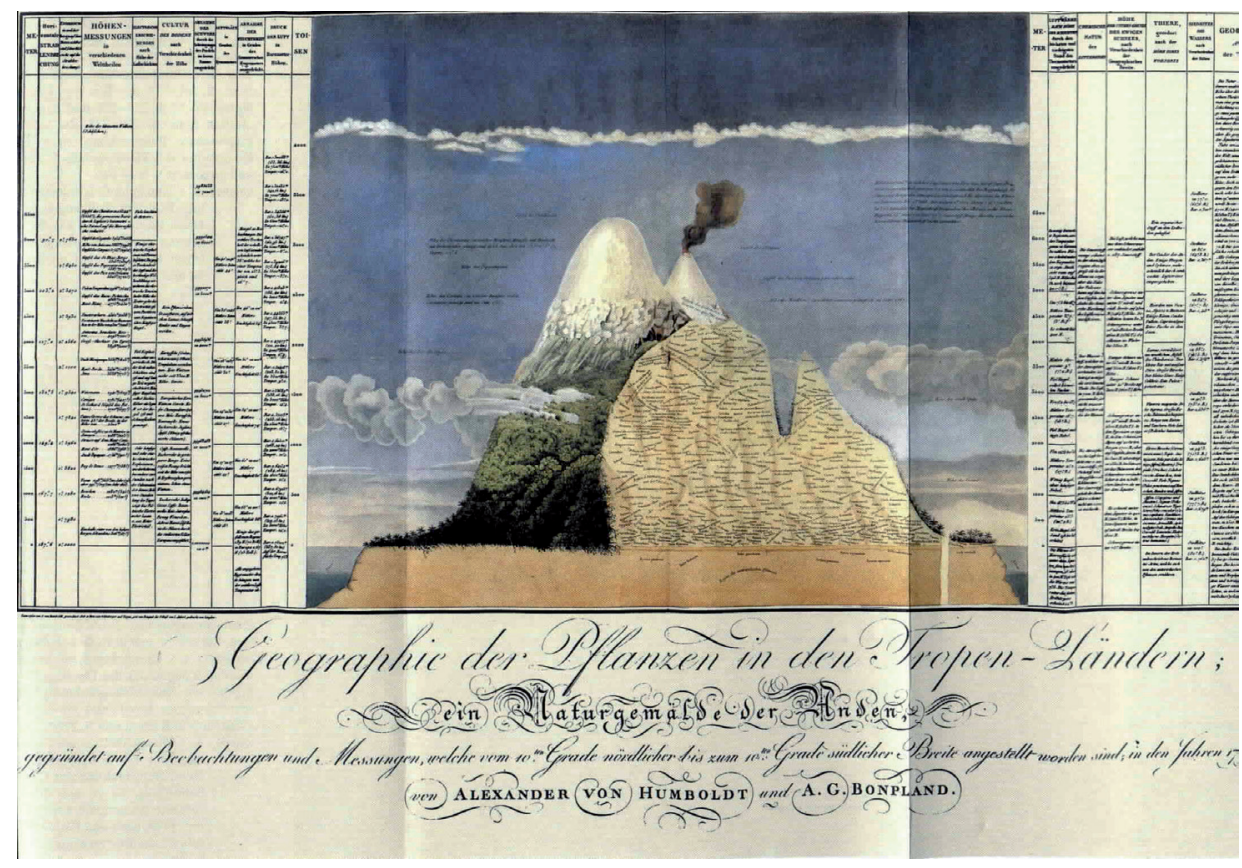

Figura 4. Alexander von Humboldt: Géographie des plantes équinoxiales. Tableau physique des Andes et Pays voisins, 1803. Acuarela. Fuente: A. von Humboldt (1807).

\subsection{La aplicación del modelo de montaña insular en Sierra Nevada}

Clemente Rubio también consideró el estudio de la geografía de plantas de Sierra Nevada. Como buen conocedor del modelo de los pisos de vegetación, concedió un valor primordial al estudio de la altitud de la montaña como variable indispensable para "formar una escala vegetal" del macizo. Fue el primer científico que llevó a cabo un estudio de la botánica de la Sierra mediante el método de la zonificación altitudinal de la montaña. Además, fue consciente de la circulación de tal modelo metodológico, ya que él mismo comparó sus trabajos con los del "célebre Barón de Humboldt", quien, "con más medios y conocimientos que yo, abarcaba en grande la del Nuevo Mundo" (Clemente y Rubio, 1863, 3-4).

En su trabajo Tentativa sobre la Liquenología geográfica de Andalucía, Clemente Rubio configuró las “zonas geográfico-botánicas del suelo andaluz”, una tabla donde mostró las especies botánicas y sus relaciones con las diferentes altitudes del territorio. En ellas, incluyó "las tablas geográfico-vegetales" de la Sierra, comenzando con la clasificación de la liquenología (Clemente y Rubio, 1863, 5). Para ello, Clemente Rubio dividió "la altura del suelo andaluz en seis zonas". Sus observaciones le condujeron a conclusiones novedosas para la época, relacionadas no solo con la altitud del macizo, sino también con sus condiciones climatológicas, vinculadas, a su vez, con su latitud y su orientación: "que el más alto grado de calor de Europa, aunque esté acompañado del 
mayor grado de sequedad, es más favorable á la vegetación de los líquenes, al menos en la vecindad del mar, que el frio de las nieves perpetuas y de la zona inferior á ellas, y tanto ó más que el temperamento mismo de la zona alpina, aunque estén acompañados del grado de humedad más proporcionado á su vegetación" (Clemente y Rubio, 1863, 8, énfasis en original). Como conclusión a su estudio de los líquenes, el científico español, aun sirviéndose de las herborizaciones efectuadas en el Pirineo y los Alpes, supo establecer una diferenciación de la biogeografía de Sierra Nevada con respecto de las de aquellas cordilleras continentales, teniendo en cuenta la ubicación de la alta montaña nevadense en la zona macroclimática mediterránea $(1863,11)$ : “aun prescindiendo de las diferencias que debe producir en la zona que una planta abarca la diferencia de latitud, y que el ilustre Ramond ha procurado determinar, hay otras causas que influyen en que no siempre aparezca la propia, ni aun siquiera una análoga, en diversos países ni en el mismo: el temperamento, que es á mi entender la causa principal, hace que difiera notablemente la escala vegetal del Norte de una sierra de la del Mediodía”.

El moderno planteamiento de Clemente Rubio constituyó un referente fundamental para las posteriores investigaciones biogeográficas en Sierra Nevada. En 1837, el botánico Edmond Pierre Boissier (1810-1885) acudió al macizo granadino con el objetivo de estudiar la geografía de plantas de la región bética. Allí, continuó con la propuesta de Clemente Rubio, dotándola de su propia manifestación gráfica, la cual emparentaría a la Sierra con el modelo humboldtiano de montaña insular. Fruto de sus expediciones al macizo, publicó, entre 1839 y 1845, en dos tomos, Voyage botanique dans le midi de l'Espagne pendant l'année 1837. El primero contenía el relato de sus expediciones al Reino de Granada, especialmente a las montañas de Sierra Nevada, mientras que el segundo ofrecía un extenso catálogo ilustrado de las plantas halladas.

El 2 de julio de 1837, el botánico suizo emprendió su primera ascensión al Picacho del Veleta. En ella, Boissier empleó el procedimiento comparativo, establecido por Humboldt, según el cual tomó como referencia los estudios sobre las geografías de plantas de los Alpes en su investigación botánica de Sierra Nevada. La realidad biogeográfica de la Sierra se ajustó así a los modelos hegemónicos que la ciencia había construido a partir del análisis de la alta montaña europea. Gran parte de las especies recolectadas y clasificadas se encontraron "todas, sin excepción, [en] la flora de los altos Alpes de Suiza": "Comparando [...] esta zona superior de la Sierra Nevada con aquella que le corresponde en los Alpes, encontramos la confirmación de esta ley que la variedad de la vegetación en las altas montañas se halla en proporción a la extensión que ellas ocupan" (Boissier, 1839, I, 126).

En su ordenación botánica de Sierra Nevada, Boissier adoptó el paradigma humboldtiano de los pisos de vegetación de la montaña, para lo que extrapoló el modelo de representación de los tableaux physiques al estudio del macizo. La litografía en color Tableau synoptique des Hauteurs et Limites des Végétaux les plus caractéristiques dans le royaume de Grenade, incluida en su Voyage botanique, representó el perfil del territorio granadino desde el nivel del mar hasta los casi 11000 pies que se otorgaba al Mulhacén (Fig. 5). En ella, el suizo ordenó las plantas y flores que encontró atendiendo al criterio bioclimático altitudinal. El perfil estaba estructurado en distintas franjas horizontales de 
altitud, comprendiendo cada una los mil pies. Los nombres de las plantas fueron minuciosamente colocados por el interior de las franjas, respondiendo a los cuatro pisos de vegetación, diferenciados por colores, propuestos por el científico suizo: la zona cálida, la zona montañosa, la zona alpina y la zona glacial.

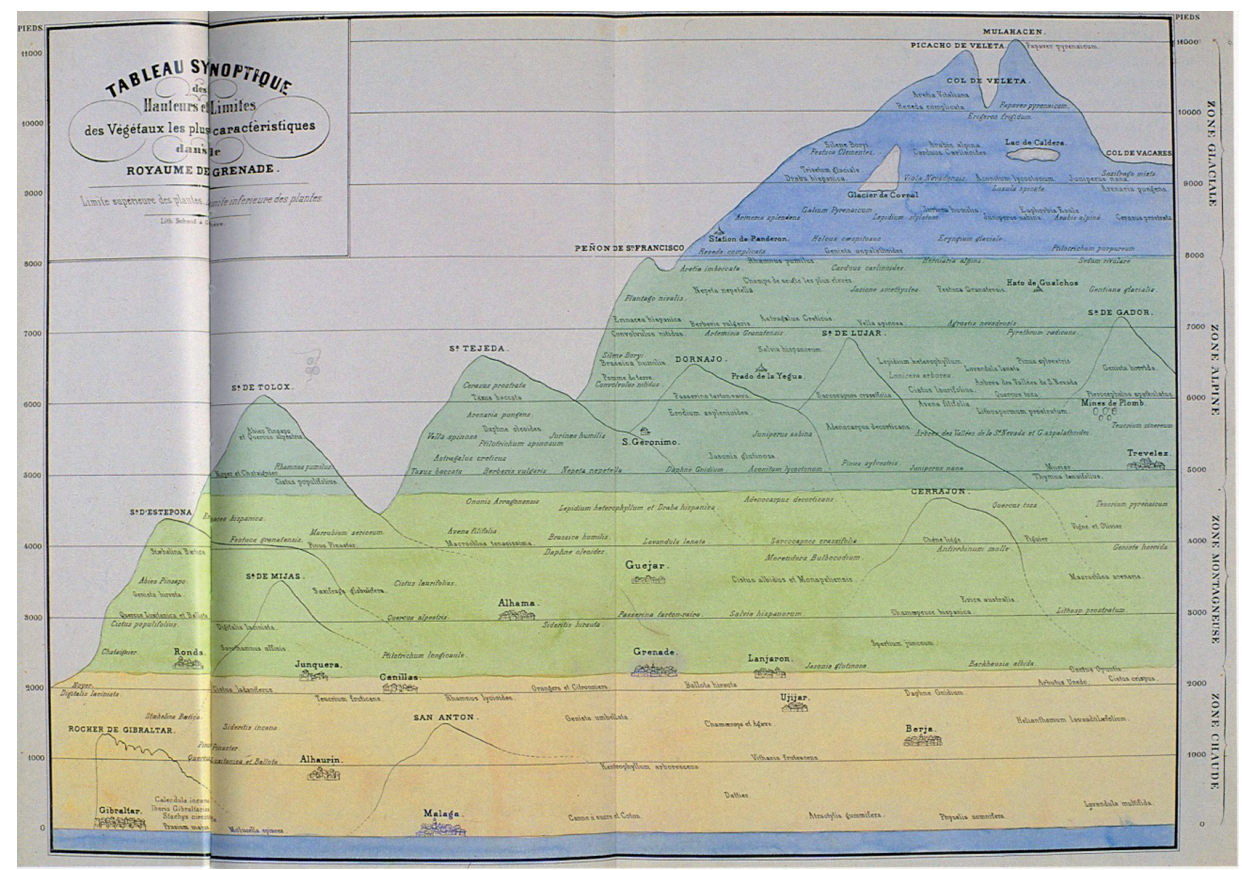

Figura 5. Charles Edmond Boissier: Tableau synoptique des Hauteurs et Limites des Végétaux les plus caractèristiques dans le royaume de Grenade, 1839. Litografía en color. Fuente: Boissier (1839-1845).

Asimismo, la litografía presentaba una comparativa de las altitudes de las distintas sierras béticas que culminaban en las cumbres de Sierra Nevada. Las sierras aparecían dispuestas de manera lineal en un mismo plano, permitiendo una fácil comparación visual. Este estudio comparativo entre las distintas sierras béticas reflejó el interés del suizo por elaborar "una idea general de la vegetación" de Andalucía Oriental, para abordar luego una "descripción más científica y razonada de esta misma vegetación, considerada en sus diversas zonas y sus relaciones con los países vecinos". Proyectó así un estudio biogeográfico de Sierra Nevada y sus sistemas adyacentes que fuera susceptible "de guiar a los naturalista que pudieran tener la tentación, en el futuro, de visitar algunas de estas regiones favorecidas por la naturaleza y colmados por ella con sus más ricos tesoros" (Boissier, 1839, T. I, IV). Con ello, Boissier hizo de Sierra Nevada una montaña insular que funcionó como un paradigma de la riqueza florística del continente, y planteó un estudio que pudiera circular en el ámbito científico de su tiempo, al igual que había circulado el propio modelo en que se basaba. 


\section{Conclusiones y discusión}

El presente artículo ha mostrado cómo los modelos de representación, los procedimientos metodológicos y las prácticas científicas del primer conocimiento geológico y biogeográfico europeo circularon desde diversas cordilleras foráneas hasta las cumbres de Sierra Nevada, contribuyendo a la construcción del primer discurso geográfico moderno de la alta montaña nevadense. Por un lado, la nueva manera de formular fisiográfica y geológicamente la alta montaña por medio de la mirada panorámica desde las cumbres; y, por otro, el concepto biogeográfico de montaña insular, encontraron en Sierra Nevada un nuevo lugar de aplicación. La transmisión del conocimiento mediante "volúmenes de imágenes impresas y reproducidas", en los que yacieron "redes de intercambio" entre las ideas de unos científicos y otros, hizo del macizo un espacio de recepción y producción del conocimiento europeo de la alta montaña (Withers y Livingstone, 2011, 11).

En su estudio geográfico del macizo nevadense, Clemente Rubio asimiló el procedimiento de la visión global sobre los cordales de montañas, practicado por Saussure en los Alpes y por Ramond en los Pirineos. Sus croquis y dibujos sirvieron de apoyo para emprender el análisis topográfico de Sierra Nevada, examinar la disposición de sus complejos rocosos y conocer el orden de sus componentes geográficos, constituyendo herramientas gráficas para la conceptualización del macizo como sistema. Asimismo, Clemente Rubio concibió Sierra Nevada como un espacio de una extraordinaria riqueza botánica. Para ello, empleó el modelo metodológico de los pisos altitudinales de vegetación elaborado por Humboldt en su estudio del Chimborazo.

Unos años más tarde, Boissier recogió la herencia de la contribución de Clemente Rubio. En el trabajo del científico suizo, las particularidades biogeográficas de Sierra Nevada fueron clasificadas en un extenso catálogo de especies botánicas, elaborando un estudio sistemático de su geografía de plantas y otorgándole a dicha categorización su expresión iconográfica más evidente. Mediante la aplicación del prototipo humboldtiano de la montaña insular bioclimática de pisos de vegetación, su interpretación naturalista de la Sierra quedó formulada en el Tableau synoptique de la geografía del Reino de Granada, donde planteó una visión excepcionalista de la montaña basada en su riqueza de especies botánicas.

Sin embargo, las ideas y los modelos no son solo transmitidos y relocalizados en otros lugares, sino que, al mismo tiempo, son reinterpretados atendiendo a diversos factores, tales como las propias particularidades geográficas de aquellos espacios de recepción (Livingstone, 2005). Por ello, si los espacios geográficos no deben ser pensados como "meros contenedores y territorios" en los que tiene lugar la actividad intelectual (Withers y Livingstone, 2011, 2), teniendo en cuenta los particularismos geográficos de Sierra Nevada, que la diferencian de sus cordilleras continentales de referencia, ¿cabría pensar que los modelos aplicados a partir de ejemplos de otras tipologías de alta montaña se vieron transformados por la propia realidad geográfica de la Sierra? Ahora bien, ¿cómo se produjo dicha reinterpretación? Como consecuencia, ¿se produjo una valoración sesgada del macizo, provocada por la aplicación de modelos foráneos, impidiendo un estudio diferenciado de los particularismos de la montaña nevadense? 
El artículo ha mostrado que hubo una transmisión del procedimiento visual e iconográfico empleado en los estudios geográficos de los Alpes y Pirineos al sector de Sierra Nevada. No obstante, y considerando las diferencias técnicas entre unas imágenes (panorámicas acabadas e impresas) y otras (croquis inéditos en su época), se puede inferir que los formatos panorámicos de las cordilleras europeas se readaptaron a la realidad geográfica del macizo nevadense. De esta forma, mientras que las descripciones de Ramond destacaron las variaciones de la disposición rocosa del Monte Perdido, los croquis de Clemente Rubio hicieron patentes la uniformidad de la capa esquisto-micácea de las cumbres de la Sierra. Asimismo, si Saussure y Ramond realzaron en sus modelos la morfología de los Alpes y los Pirineos, el botánico español, quizá debido al atípico relieve del macizo, producto de la fuerte erosión fluvial, y a su carencia de masas glaciares, evidenció una falta de interés por el estudio exhaustivo del modelado glaciar de la vertiente norte de la Sierra. En cambio, prestó más atención a las lagunas de alta montaña y los grandes barrancos, rasgos específicos del macizo bético.

La aplicación del modelo visual de Humboldt al estudio de la Sierra parece evidente. Sin embargo, mientras que los perfiles de Humboldt expresaron el dinamismo continuo de la naturaleza, la lámina de Boissier parecía transmitir, en cambio, un orden lineal de las especies botánicas de la región bética, algo distinta al continuo de la naturaleza expresado en las acuarelas del prusiano. Si estas últimas revelaron un espacio desordenado donde las especies aparecían imbricadas unas con otras, la imagen de Boissier, por el contrario, parecía encarnar una montaña ordenada a la manera taxonómica -es decir, linneana-, en cuyo espacio los nombres de las plantas fueron ubicados sin permitir una interconexión real entre ellas. El botánico suizo planteó así una montaña ordenada según el modelo linneano, manifestado de forma más evidente en el catálogo de las especies que incluyó en el segundo tomo de su obra, Énumération des plantes du Royaume de Grenade. Boissier aplicó la imagen de la biogeografía fundada por Humboldt sin contemplar, por ello, los mismos principios epistemológicos. Su imagen de la Sierra constituyó la manifestación gráfica de la clasificación linneana del macizo a través del modelo humboldtiano de montaña insular.

Los modelos del primer conocimiento geográfico de la montaña asimilados en Sierra Nevada se correspondieron con un patrón hegemónico, encarnado por la alta montaña europea y equinoccial. De esta manera, Clemente Rubio utilizó las últimas investigaciones sobre los Alpes, desarrolladas por Saussure y Gimbernat, en su aproximación al análisis fisiográfico del macizo. Asimismo, se apoyó en las observaciones de Ramond en el Monte Perdido para diferenciar entre los materiales primitivos, secundarios y otros de transición en su aportación al estudio geológico de Sierra Nevada. Por su parte, Boissier tomó como referencia los pisos bioclimáticos planteados en los Alpes, basados, a su vez, en el modelo humboldtiano de la montaña equinoccial. Las características geológicas y biogeográficas del macizo nevadense se revelaron así a través de los prototipos científicos de su tiempo. No obstante, si bien aquellas cordilleras extrapeninsulares conformaron el canon para el estudio de Sierra Nevada, Clemente Rubio observó diferencias con respecto al prototipo de alta montaña continental. Debido a su conocimiento de la realidad geográfica del macizo, fue consciente de las limitaciones de la aplicación de aquellos modelos, como afirmó en sus anotaciones. Por las propias particularidades de la Sierra 
como un macizo de alta montaña mediterránea, se produjo una variación de las ideas científicas originales en el espacio de recepción. Clemente Rubio destacó así algunos elementos que caracterizan a Sierra Nevada como un macizo altamente condicionado por su ubicación en una zona macroclimática mediterránea.

Atendiendo, por tanto, a los procesos de reinterpretación sufridos por unos modelos científicos de representación en espacios geográficos ajenos en la movilidad del discurso científico, se puede afirmar que Sierra Nevada emergió como una montaña de recepción del primer conocimiento geográfico europeo. Pero, a su vez, es preciso considerar que este se forjó a través de un diálogo entre el paradigma foráneo de alta montaña y la propia geograficidad del macizo. Al mismo tiempo que se construía su formulación científica en términos alpinos, su pertenencia a una zona climática mediterránea posibilitó una aproximación a su interpretación como una montaña compleja, dominada por una imbricación de factores que la sitúan entre lo continental y lo meridional.

\section{Referencias}

Beattie, A. 2006. The Alps: A Cultural History. Oxford University Press, Oxford.

Beer, G. 1996. Translation or transformation? The relations of literature and science. En Open Fields: Science in Cultural Encounter, Oxford University Press, Clarendon, pp. 173-195.

Beraldi, H. 1977. Cents ans aux Pyrénées. Les Amis du Livre Pyrénéen, Pau.

Boissier, Ch.E. 1839-1845. Voyage botanique dans le midi de l'Espagne pendant l'anne 1837. Gide et Cie., Paris.

Briffaud, S. 1989. Naissance d'un paysage. L'invention géologique du paysage pyrénéenn à la fin XVIIIe siècle. Revue de Synthèse 3-4, 419-452.

Briffaud, S. 1994. Naissance d'un paysage. La montagne pyrénéenne à la croisée des regards (XVIIe-XIXe siècles). AGM, Université de Toulouse II, Toulouse.

Briffaud, S. 2006. Le temps du paysage. Alexandre de Humboldt et la géohistoire du sentiment de la nature. En Géographies plurielles. Les sciences géographiques au moment de l'émergence des sciences humaines (1750-1850), H. Blais, I. Laboulais (eds.), L'Harmattan, Paris, 275301.

Broc, N. 1969. Les Montagnes vues par les géographes et les naturalistes de langue française au XVIIIe siècle. Bibliothèque Nationale, Paris.

Broc, N. 1991. Les montagnes au siècle des lumières. Perception et représentation. Comité des Travaux historiques et scientifiques, Paris.

Buttimer, A. 2001. Beyond Humboldtian science and Goethe's way of science: challenges of Alexander von Humboldt's Geography. Erdkunde 55 (2), 105-120.

Capel, H. 1981. Filosofía y ciencia en la geografía contemporánea. Barcanova, Barcelona.

Capel Sáez, H. 2002. El viaje científico andaluz de Simón de Rojas Clemente Rubio: de la historia natural a la geografía». En Viaje a Andalucía: «Historia natural del reino de Granada» (1804-1809), S. de R. Clemente y Rubio, (A. Gil Albarracín, ed.), Griselda Bonet Girabet, Almería, pp. 17-46.

Clemente y Rubio, S. de R. 1827. "Geografía del reino de Granada" y un apéndice sobre la nivelación de Sierra Nevada. Granada. Archivo del Real Jardín Botánico, Madrid. Div., leg. 6 y 7.

Clemente y Rubio, S. de R. 1863. Tentativa sobre la Liquenología geográfica de Andalucía, por D. Simón de Rojas Clemente. Trabajo ordenado conforme á los manuscritos del autor, por D. Miguel Colmeiro. Revista de los progresos de las Ciencias 14 (1), 3-22. 
Clemente y Rubio, S. de R. 2002. Viaje a Andalucía: "Historia natural del reino de Granada" (1804-1809), A. Gil Albarracín (ed.), Griselda Bonet Girabet, Almería.

Comment, B. 2002. The panorama. Reaktion, London.

Cornejo Nieto, C. 2014. "Geografías de recepción" de los imaginarios geográficos alpinos: representaciones y narrativas de Sierra Nevada (s. XIX). Cuadernos Geográficos 53 (1), 5-35.

Cosgrove, D.E. 2008. Geography and Vision: Seeing, Imagining and Representing the World. I.B. Tauris, London.

Della Dora, V. 2011. Imagining Mount Athos: Visions of a Holy Place from Homer to World War II. University of Virginia Press, Charlottesville.

Dettelbach, M. 1999. The face of Nature: precise measurement, mapping, and sensibility in the work of Alexander von Humboldt. Studies in History and Philosophy of Science Part C: Studies in History and Philosophy of Biological and Biomedical Sciences 30 (4), 473-504.

Foucault, M. 1989. Las palabras y las cosas: una arqueología de las ciencias humanas. Siglo XXI, México D. F.

Frolova, M. 2006. Les paysages du Caucase: invention d'une montagne. CTHS, Paris.

Godlewska, A.M.C. 1999. From Enlightment vision to modern cience? Humboldt visual thinking. En Geography and Enlightenment, D. N. Livingstone, Ch. W. J. Withers (eds.), University of Chicago Press, Chicago, pp. 236-75.

Gómez Mendoza, J., Sanz Herráiz, C. 2010. De la biogeografía al paisaje en Humboldt: pisos de vegetación y paisajes andinos equinocciales. Población \& Sociedad 17, 29-57.

Gómez Ortiz, A. 2004. El conocimiento glaciar de Sierra Nevada: de la descripción ilustrada del siglo XVIII a la explicación científica actual. Reial Acadèmia de Doctors, Barcelona.

Gómez Ortiz, A., Milheiro Santos, B., Serrano Giné, D. 2008. Nieves, hielos y aguas en los paisajes de Sierra Nevada: el interés de la información gráfica de los libros de época. Cuadernos de Investigación Geográfica 34, 101-118.

Gómez Ortiz, A., Plana Castellví, J.A. 2006. La pequeña Edad del Hielo en Sierra Nevada a partir de los escritos de la época (siglos XVIII y XIX) y relaciones con el progreso de la geografía física y geomorfología española. Boletín de la Asociación de Geógrafos Españoles, 42, 71-98.

González Trueba, J.J., Serrano Cañadas, E. 2007. Cultura y naturaleza en la Montaña Cantábrica. Servicio de Publicaciones de la Universidad de Cantabria, Santander.

Guichonnet, P., Vellozzi, M.C., Joutard, P., Vercken, M.T., Lebailly, H. 2002. Mont-blanc: conquête de l'imaginaire. La Fontaine de Siloë, Montmélian.

Humboldt, A. von 1807. Essai sur la géographie des plantes, accompagné d'un tableau physique des régions équinoxales, Fondé sur des mesures exécutées, depuis le dixième degré de latitude boréale jusqu'au dixième degré de latitude australe, pendant les années 1799, 1800, 1801, 1802 et 1803. Tubingen: chez Fr. Schoell, Paris.

Jardine, N., Secord, J.A., Spary, E.C. (eds.). 1995. Cultures of Natural History. Cambridge University Press, Cambridge.

Joutard, P. 1986. L'invention du Mont Blanc. Gallimard, Paris.

Livingstone, D. 2003. Putting Science in Its Place: Geographies of Scientific Knowledge. University of Chicago Press, Chicago.

Livingstone, D. 2005. Science, text and space: thoughts on the geography of reading. Transactions of the Institute of British Geographers 30 (4), 391-401.

Mac Neill, J.R. 1992. The Mountains of the Mediterranean World: an Environmental History. Cambridge University Press, Cambridge.

Martínez de Pisón, E. 1998. Imagen del paisaje: la generación del 98 y Ortega y Gasset. Caja Madrid Obra Social, Madrid. 
Mateu Bellés, J.F. 2008. Descubrimiento científico del paisaje. En Retorno al paisaje. El saber filosófico, cultural y científico del paisaje en España, J. F. Mateu Bellés, M. Nieto Salvatierra (eds.), EVREN, Valencia, pp. 347-387.

Naranjo Ramírez, J., López Ontiveros, A. 2011. La obra gráfica de Juan Carandell Pericay sobre Cataluña. Scripta Nova. Revista Electrónica de Geografía y Ciencias Sociales. Disponible en: http://www.ub.es/geocrit/sn/sn-363.htm.

Ortega Cantero, N. 2001. Paisaje y excursiones. Francisco Giner, la Institución Libre de Enseñanza y la Sierra de Guadarrama. Raíces, Madrid.

Ortega Cantero, N. 2012. Naturaleza, cultura y símbolo: la imagen de la montaña de Peñalara en el paisajismo español moderno. Cuadernos Geográficos 51, 96-113.

Pauwels, L. 2006. Introduction: the role of visual representation in the production of scientific reality. En Visual Cultures of Science: Rethinking Representational Practices in Knowledge Building and Science Communication, L. Pauwels (ed.), Dartmouth College Press, Hanover, pp. vii-xix.

Ramond de Carbonnières, L. 1789. Observations faites dans les Pyrénées, pour servir de suite à des observations sur les Alpes, insérées dans une traduction des Lettres de W Coxe, sur la Suisse. Chez Belin, Paris.

Ramond de Carbonnières, L. 1801. Voyages au Mont-Perdu et dans la partie adjacente des Hautes-Pyrénées. Chez Belin, Paris.

Reichler, C. 2002. La découverte des Alpes et la question du paysage. Georg, Genève.

Ring, J. 2000. How the English Made the Alps. Murray, London.

Rupke, N. 2000. Translation studies in the history of science: the example of Vestiges. The British journal for the history of science 33 (2), 209-222.

Said, E. W. 1991. Traveling theory. En The World, the Text and the Critic. Vintage, London, pp. 226-247.

Saule-Sorbé, H. 1993. Pyrénées. Voyage par les images. Faucompret, Serres-Castet.

Saule-Sorbé, H. 2010. Arte y geografía en las representaciones modernas del paisaje: el caso de los Pirineos. Estudios geográficos 71 (269), 475-504.

Saussure, H.B. de. 1779. Voyages dans les Alpes: précédés d'un essai sur l'histoire naturelle des environs de Geneve. Vol. III. Chez Louis Fauche-Borel, Neuchâtel.

Secord, J.A. 2004. Knowledge in transit. Isis 95 (4), 654-672.

Secord, A. 2011. Pressed into service: specimens, space, and seeing in botanical practice. En Geographies of Nineteenth-Century Science, Ch.W.J Withers, D.N. Livingstone, University of Chicago Press, Chicago, pp. 283-310.

Stafford, B.M. 1984. Voyage into Substance: Art, Science, Nature, and the Illustrated Travel Account, 1760-1840. MIT Press, Cambridge.

Titos Martínez, M. 1997. Sierra Nevada: una gran historia. Vols. I y II. Universidad de Granada, Granada.

Walter, F. 2005. La montagne alpine: un dispositif esthétique et idéologique à l'échelle de l'Europe. Revue d'Histoire moderne et contemporaine 52 (2), 64-87.

Withers, Ch.W.J., Livingstone, D.N. 2011. Thinking geographically about nineteenth-century science. En Geographies of Nineteenth-Century Science, Ch.W.J. Withers, D.N. Livingstone (eds.), The University of Chicago Press, Chicago, pp. 1-20. 